\title{
An Ion/Molecule Reaction for the Identification of Analytes with Two Basic Functional Groups
}

\author{
Mingkun Fu, Penggao Duan, Sen Li, Ryan J. Eismin, and \\ Hilkka I. Kenttämaa \\ Department of Chemistry, Purdue University, West Lafayette, Indiana, USA
}

A mass spectrometric method is presented for the identification of analytes with two basic functionalities and PA between 222 and $245 \mathrm{kcal} / \mathrm{mol}$, including diamines. This method utilizes gas-phase ion-molecule reactions of protonated analytes with neutral 1,1-diethoxyethene (DEE) in a Fourier transform ion cyclotron resonance mass spectrometer (FT-ICR). A variety of protonated mono-, bi-, and trifunctional analytes containing different functional groups, namely, amido, amino, N-oxide, hydroxy, carboxylic acid, keto, thio, thioether, alkene, phosphite, and phosphonate, were tested in the FT-ICR. The results demonstrate that basic protonated bifunctional compounds (PA between 222 and $245 \mathrm{kcal} / \mathrm{mol}$ ) react selectively with $\mathrm{DEE}$ by forming a specific addition/elimination product ion (adduct - EtOH) (this product was also observed for lysine with three functionalities). The diagnostic reaction sequence involves proton transfer from the protonated analyte to the basic vinyl group in DEE, followed by addition of one of the functional groups of the analyte to the electrophilic $\alpha$-carbon in protonated DEE. The next step involves proton transfer from this functionality to the other analyte functionality, followed by proton transfer to DEE and elimination of ethanol. Since the mechanism involves proton transfer between two functional groups of the analyte, the reaction does not occur for analytes where the two functionalities cannot be in close proximity (i.e., meta-phenylenediamine), and where no proton is available (i.e., dimethylaminoketone). (J Am Soc Mass Spectrom 2009, 20, 1251-1262) () 2009 Published by Elsevier Inc. on behalf of American Society for Mass Spectrometry

$\mathrm{D}$ evelopment of analytical methods for rapid and accurate structural characterization of unknown organic compounds is important for many fields, including drug discovery [1]. Several techniques, including NMR, FT-IR, and X-ray crystallography, are commonly utilized for identification of previously unknown compounds [2a]. However, these techniques require relatively large quantities of analytes, and FT-IR and X-ray crystallography techniques are not applicable to complex mixtures [2b]. Tandem mass spectrometry (MS/MS) is a powerful tool for fast direct mixture analysis. Historically, MS/MS experiments rely on isolation of a protonated analyte and its exposure to activating collisions to generate structurally informative fragment ions (collision-activated dissociation or CAD) [3]. While extremely powerful in identification of known compounds, this method cannot usually provide detailed structural information for unknown analytes (not already in MS libraries), such as the type and number of different functionalities present in the analyte.

Address reprint requests to Dr. H. I. Kenttämaa, Department of Chemistry, Purdue University, BRWN Building, 560 Oval Dr., West Lafayette, IN 47907, USA. E-mail: hilkka@purdue.edu
MS/MS methods based on gas-phase ion-molecule reactions can provide very detailed structural information $[4,6 a]$. In some cases, this approach has been combined with collision-activated dissociation (CAD) of the ion-molecule reactions' products to obtain even more information [5]. Thus far, the majority of studies on structurally diagnostic ion-molecule reactions have focused on the identification of functionalities in neutral analytes by using selective ionic reagents [5]. For example, gas-phase reactions of dimethoxyborenium ion followed by $\mathrm{CAD}$ and/or $\mathrm{H} / \mathrm{D}$ exchange reactions have been demonstrated to allow the identification of functional groups present in neutral alcohols, aldehydes, ethers, ketones, and some biologically active molecules containing hydroxyl groups [5]. Much fewer studies have focused on the use of a neutral reagent to identify the functionalities in protonated analytes [6-8]. However, this approach is needed for mass spectrometric analyses involving the widely used electrospray ionization (ESI), atmospheric pressure chemical ionization (APCI), or matrix-assisted laser desorption/ionization (MALDI) methods [7]. Neutral reagents have been developed for the identification of epoxy, primary $\mathrm{N}$ oxide, amido, hydroxy, ether, ester, and keto functionalities in protonated mono- and polyfunctional analytes
(C) 2009 Published by Elsevier Inc. on behalf of American Society for Mass Spectrometry. 1044-0305/09/\$32.00

doi:10.1016/j.jasms.2009.02.020
Published online February 21, 2009

Received October 8, 2008

Revised February 13, 2009 Accepted February 13, 2009 
[6]. For example, ( $N, N$-diethylamino)dimethylborane can be used to identify the protonated amido functionality [6d]. Further, hydriodic acid has been reported to attach to neutral basic sites in polypeptide ions in the gas phase. These reactions can be used to determine the number of neutral basic sites, including lysine, arginine, histidine, and N-termini [8]. In the work presented here, 1,1-diethoxyethene (DEE) is demonstrated to react in a selective manner with protonated analytes with two basic functional groups, such as diamines, in a Fourier transform ion cyclotron resonance mass spectrometer (FT-ICR).

\section{Experimental}

\section{Instrumentation}

All experiments were performed using an Nicolet model FTMS-2000 dual-cell FT-ICR mass spectrometer equipped with a 3-Tesla superconducting magnet, and a Finnigan Odyssey data station, as described previously [9]. All chemicals used were purchased from the Sigma-Aldrich Company (St. Louis, Mo) and used as received. Analytes were introduced into one cell region by using a solids probe, a Varian (Palo Alto, CA) leak valve, or a Finnigan-built batch inlet system equipped with a variable leak valve. The analytes were protonated by self-chemical ionization, which was accomplished by allowing the molecular ion and the ionic fragments generated upon electron ionization $(20 \mathrm{eV}, 7$ $\mu \mathrm{A}, 50-500 \mathrm{~ms})$ of the analyte, to react with the neutral analyte molecules for a certain period of time $(\sim 3.0 \mathrm{~s})$. Nominal pressure of the neutral analyte in the cell, as measured by a Bayard-Alpert ion gauge, varied between $0.5 \times 10^{-8}$ and $9 \times 10^{-8}$ Torr. After this, all the ions in the other side of the dual cell were removed by changing the remote trapping plate voltage from $+2.0 \mathrm{~V}$ to $-3.5 \mathrm{~V}$ for $12 \mathrm{~ms}$. The protonated analyte was transferred into the other cell by grounding the conductance limit plate (75-140 $\mu \mathrm{s})$, followed by cooling for a period of about $1 \mathrm{~s}$ via IR emission [10] and collisions with Ar present at about $10^{-5}$ torr. The protonated analyte was isolated by using a stored-waveform inverse Fourier transform [11] (SWIFT) excitation pulse to eject all unwanted ions, and was allowed to react for a variable period of time with neutral DEE introduced into the same cell through a variable leak valve. Nominal pressure of DEE in the cell, as measured by a Bayard-Alpert ion gauge, was 1.1-6.9 $\times 10^{-8}$ Torr. Some of the derivatization products were further probed by subsequent isolation via SWIFT followed by sustained off-resonance irradiated collision-activated dissociation [12] (SORI-CAD). SORI-CAD experiments utilized off-resonance excitation of the isolated ion at a frequency $\pm 1000 \mathrm{~Hz}$ off the cyclotron frequency of the ion. This experiment was carried out by subjecting the desired ion to an off-resonance excitation pulse with an amplitude between 0.19 and $1.1 \mathrm{~V}$ for $300 \mathrm{~ms}$ during which collisions with argon $\left(\sim 10^{-5}\right.$ Torr $)$ occur. After reactions, all ions were excited for detection by using chirp excitation with a bandwidth of $2.7 \mathrm{MHz}$, and a sweep rate of $3200 \mathrm{~Hz} \mathrm{ss}^{-1}$. The spectra were recorded as $64 \mathrm{k}$ data points and subjected to Hanning apodization, followed by augmentation of the data by using one zero-fill before Fourier transformation. All spectra were corrected by subtraction of a background spectrum recorded by removing the reactant ion by SWIFT ejection before reaction to make sure that the observed products were generated from the desired ion population.

\section{Kinetics}

In the ion-molecule reactions described above, the neutral reagent was present in vast excess to the ion of interest. As a result, these reactions inherently follow pseudo-first-order kinetics. Kinetic data were obtained by allowing the protonated analyte to react with the neutral reagent for variable periods of time (from 0.5 up to $50 \mathrm{~s})$ at a constant pressure before excitation and detection. The second-order reaction rate constant $\left(k_{\text {reaction }}\right)$ was derived from the concentration of the neutral reagent and the negative slope of the plot of the natural logarithm of the relative abundance of the protonated analyte ions versus time. The collision rates $\left(k_{\text {collision }}\right)$ were estimated by using the parameterized trajectory theory of Su and Chesnavich [13]. The overall efficiency of each reaction is given as $k_{\text {reaction }} / k_{\text {collision }}$ (i.e., the percentage of collisions leading to product formation). The reagent pressure readings of the ion gauges were corrected for the sensitivity of the ion gauge towards the neutral reagent (DEE) and its distance from the center of the ICR cell [14]. These correction factors were obtained by measuring the rate of the highly exothermic electron-transfer reaction between $\mathrm{CS}_{2}{ }^{-+}$and DEE. This highly exothermic electron-transfer reaction is assumed to proceed at the collision rate; therefore, its efficiency is assumed to be $100 \%$.

\section{Computational Studies}

Gaussian 2003 suite of programs was used in the calculations [15]. The proton affinity $(\mathrm{PA}=236 \mathrm{kcal} /$ mol) of DEE was calculated at the B3LYP/6-31G(d) level of theory by employing an isodesmic reaction scheme involving protonated methoxyethylene as the Brønsted acid [8d].

\section{Results and Discussion}

In a search for a suitable reagent, 2-methoxypropene (MOP) $\left(\mathrm{PA}^{8 \mathrm{~d}}=214 \mathrm{kcal} / \mathrm{mol}\right)$ appeared as a promising candidate since it is known to undergo a regioselective addition $/ \mathrm{MeOH}$ elimination with protonated orthodiamines $\left(\mathrm{PA}^{8 \mathrm{~d}}=214 \mathrm{kcal} / \mathrm{mol}\right)[6 \mathrm{~g}]$. However, MOP was found to be unreactive toward more basic compounds, e.g., meta-phenylenediamine $[6 \mathrm{~g}]\left(\mathrm{PA}^{8 \mathrm{~d}}=222\right.$ $\left.\mathrm{kcal} / \mathrm{mol}^{8}\right)$, diethylamine [6h] $\left(\mathrm{PA}^{8 \mathrm{~d}}=228 \mathrm{kcal} / \mathrm{mol}\right)$, 
Table 1. Products $(\mathrm{m} / \mathrm{z}$ values and branching ratios) formed in reactions between protonated aliphatic diamines and DEE (estimated $\mathrm{PA}=238 \mathrm{kcal} / \mathrm{mol})$

\begin{tabular}{|c|c|c|}
\hline Analyte $\left(m / z\right.$ of $\left.(\mathrm{M}+\mathrm{H})^{+}\right)$ & $\mathrm{PA}^{\mathrm{a}} \mathrm{kcal} / \mathrm{mol}$ & Product ions $(\mathrm{m} / \mathrm{z})$ (branching ratio) \\
\hline 1,2-Propanediamine (75) & $228^{b}$ & $\begin{array}{l}\text { Adduct - EtOH (145) (45\%) } \\
\text { DEE }+\mathrm{H}^{+}(117)(55 \%)\end{array}$ \\
\hline
\end{tabular}

2-Methyl-1,2-propanediamine (89)<smiles>CC(C)(N)CN</smiles>

1,2-trans-Cyclohexanediamine (115)<smiles>N[C@@H]1CCCC[C@H]1N</smiles>

1,2-cis-Cyclohexanediamine (115)<smiles>N[C@H]1CCCC[C@H]1N</smiles>

1,3-Propanediamine (75)<smiles>NCCCN</smiles>

2,2-Dimethyl-1,3-propanediamine (103)<smiles>CC(C)(CN)CN</smiles>

$\mathrm{N}, \mathrm{N}$-Dimethyl-1,3-propanediamine (103)<smiles>CN(C)CCCN</smiles>

1,4-Butylenediamine (89)<smiles>NCCCCN</smiles>

1,5-Pentanediamine (103)<smiles>NCCCCCN</smiles>

2-Methyl-1,5-pentanediamine (117)<smiles>CC(CN)CCCN</smiles>

1,6-Hexanediamine (117)<smiles>NCCCCCCN</smiles>

1,7-Heptanediamine (131)<smiles>NCCCCCCCN</smiles>

Adduct - EtOH (159) (61\%) $\mathrm{DEE}+\mathrm{H}^{+}$(117) (39\%)

Adduct - EtOH (185) (64\%) DEE + $\mathrm{H}^{+}(117)(36 \%)$

Adduct - EtOH (185) (62\%) $\mathrm{DEE}+\mathrm{H}^{+}$(117) $(38 \%)$

Adduct - EtOH (145) (65\%) $\mathrm{DEE}+\mathrm{H}^{+}(117)(35 \%)$

Adduct - EtOH (173) (94\%) $\mathrm{DEE}+\mathrm{H}^{+}$(117) (6\%)

Adduct - EtOH (173) (100\%)

Adduct - EtOH (159) (100\%)

Adduct - EtOH (173) (100\%)

Adduct - EtOH (187) (100\%)

Adduct - EtOH (201) (100\%) 
Table 1. Continued

\begin{tabular}{|c|c|c|}
\hline Analyte $\left(m / z\right.$ of $\left.(\mathrm{M}+\mathrm{H})^{+}\right)$ & $\mathrm{PA}^{\mathrm{a}} \mathrm{kcal} / \mathrm{mol}$ & Product ions $(\mathrm{m} / \mathrm{z})$ (branching ratio) \\
\hline 1,8-Octanediamine (145) & $237^{e}$ & $\begin{array}{l}\text { Adduct - EtOH (215) (86\%) } \\
\text { DEE }+\mathrm{H}^{+}(117)(14 \%)\end{array}$ \\
\hline
\end{tabular}

aReference [8d].

${ }^{\mathrm{b}}$ Calculated at the B3LYP/6-31G(d) level of theory, using an isodesmic reaction scheme involving 1,2-ethylenediamine as a reference Brønsted acid. ${ }^{c}$ Calculated at the B3LYP/6-31G(d) level of theory, using an isodesmic reaction scheme involving 1,3-propanediamine as a reference Brønsted acid. ${ }^{\mathrm{d} C}$ Calculated at the B3LYP/6-31G(d) level of theory, using an isodesmic reaction scheme involving 1,5-pentanediamine as a reference Brønsted acid.

${ }^{e}$ Calculated at the B3LYP/6-31G(d) level of theory, using an isodesmic reaction scheme involving 1,7-heptanediamine as a reference Brønsted acid

and quinoline [6h] $\left(\mathrm{PA}^{8 \mathrm{~d}}=228 \mathrm{kcal} / \mathrm{mol}\right)$. A similar but more basic reagent is therefore needed to promote the identification of more basic compounds (i.e., bifunctional compounds). DEE was chosen as the neutral reagent for this study due to its high proton affinity $(\mathrm{PA}=236 \mathrm{kcal} / \mathrm{mol}$; calculated at the BLYP/6-31G(d) level of theory). Furthermore, DEE has two alkoxy groups that may act as leaving groups upon reactions with highly basic protonated analytes.

A brief summary of the results is provided here, followed by an in-depth discussion of the different analytes studied. Protonated aliphatic diamines were found to react with DEE to form a diagnostic addition/ elimination product ion (adduct - EtOH) (Table 1). The efficiencies measured for the reactions of protonated aliphatic diamines with DEE are high. For example, protonated 1,3-propanediamine reacts with DEE at an efficiency of $21 \%$, protonated 1,5-pentaneamine at $78 \%$, protonated 2-methyl-1,5-pentanediamine at $75 \%$, and protonated 2,2-dimethyl-1,3-propanediamine at $80 \%$. These high reaction rates suggest that the ion-molecule reactions are fast enough for practical analytical applications. In addition, the observed proton transfer reactions suggest that the PA of DEE is actually somewhat greater than the calculated value $(236 \mathrm{kcal} / \mathrm{mol})$. The observation of proton transfer to DEE from protonated lysine $(\mathrm{PA}=238 \pm 2 \mathrm{kcal} / \mathrm{mol})$ but not from proton-

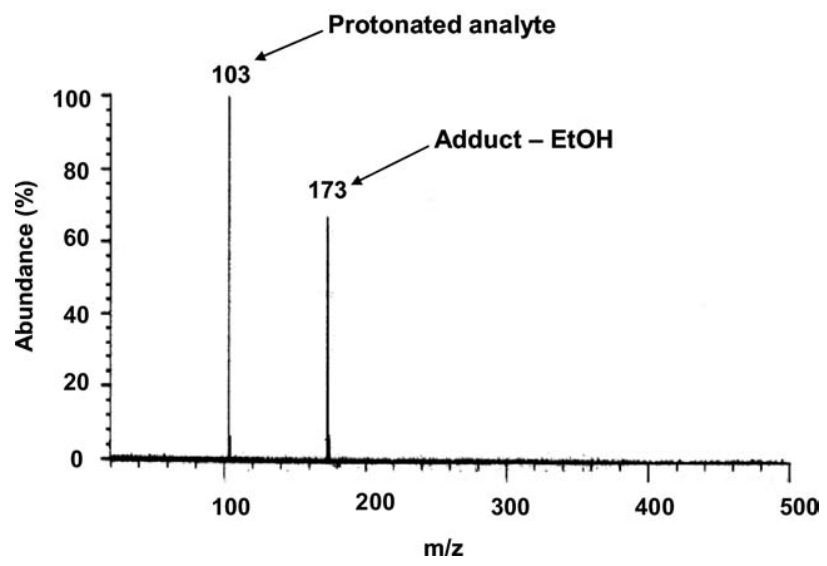

Figure 1. A mass spectrum measured after $3 \mathrm{~s}$ reaction of protonated 1,5-pentanediamine $(\mathrm{m} / \mathrm{z} 103)$ with DEE $\left(2.1 \times 10^{-8}\right.$ Torr) in FT-ICR. This reaction results in a derivatization product corresponding to addition accompanied by ethanol loss (adduct $\mathrm{EtOH})(\mathrm{m} / \mathrm{z}$ 173). ated 1,5-pentaneamine $(\mathrm{PA}=239 \pm 2 \mathrm{kcal} / \mathrm{mol})$ suggests that the PA of DEE is $238 \pm 2 \mathrm{kcal} / \mathrm{mol}$.

The examination of various additional analytes, including amides, N-oxides, mono- and triamines, aromatic diamines, amino alcohols, amino acids, amino ketone, amino thiol, amino thioether, amino alkene, phosphonate, phosphite, and oxygen-containing monoand bifunctional compounds, suggest that protonated aliphatic bifunctional compounds (and one trifunctional compound, lysine) with PA between 222 and 245 $\mathrm{kcal} / \mathrm{mol}$ react with DEE selectively by forming the addition/elimination product ion (adduct - EtOH). Protonated bifunctional analytes with PA lower than $222 \mathrm{kcal} / \mathrm{mol}$, and monofunctional analytes with PA lower than $238 \mathrm{kcal} / \mathrm{mol}$, predominantly transfer a proton to DEE, while protonated analytes with PA greater than $245 \mathrm{kcal} / \mathrm{mol}$ are unreactive. One protonated triamine $(\mathrm{PA}=245 \mathrm{kcal} / \mathrm{mol})$ was found to undergo addition and elimination of two ethanol molecules. The reactions of the different protonated analytes with DEE are discussed in more detail below.

\section{Protonated Analytes}

Aliphatic diamines. All protonated aliphatic diamines (PA ranges from 228 to $245 \mathrm{kcal} / \mathrm{mol}$ ) react with DEE by forming the diagnostic addition/elimination product (adduct - EtOH) (Table 1). These product ions are easily recognized based on their $\mathrm{m} / \mathrm{z}$ value that is 70 units greater than the $\mathrm{m} / \mathrm{z}$ value of the protonated analytes (Figure 1). No secondary reaction products were observed. In addition to the addition/elimination reactivity, some of the aliphatic diamines (1,2-propanediamine, 2-methyl-1,2-propanediamine, 1,2-trans-cyclohexanediamine, 1,2-cis-cyclohexanediamine, 1,3-propanediamine, 2,2-dimethyl-1,3-propanediamine, and 1,8-octanediamine) react with DEE via proton transfer.

The addition/EtOH elimination reaction sequence (Scheme 1) is likely initiated by proton transfer from the protonated analyte to the most basic site, the vinyl group, in DEE. This step is either slightly exothermic or endothermic by up to $\sim 7 \mathrm{kcal} / \mathrm{mol}$ for these diamines (Table 1). Slightly endothermic reactions can occur within gas-phase ion-molecule complexes due to the solvation energy provided by solvation of the ion by the neutral molecule [6b, 6d]. However, when the PA of the analyte is greater than $249 \mathrm{kcal} / \mathrm{mol}$, this reaction becomes too 

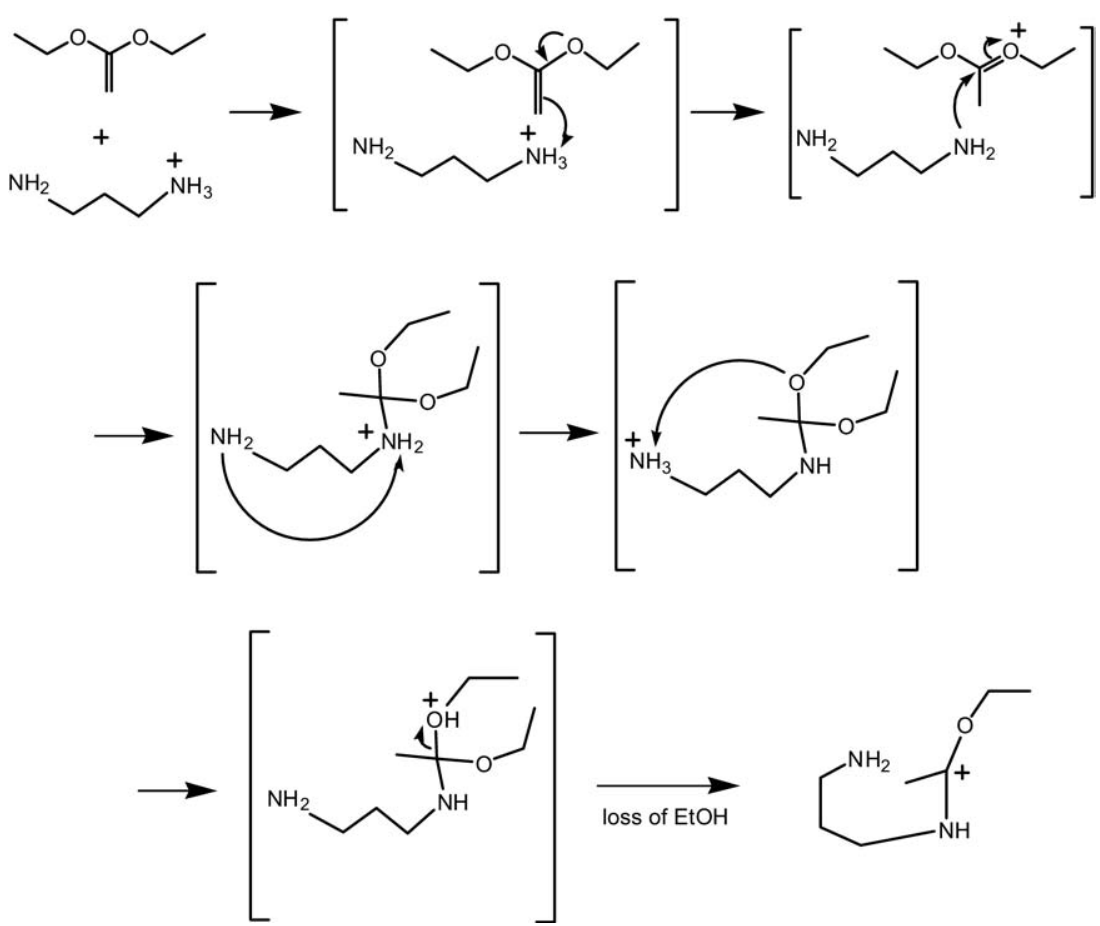

Scheme 1

endothermic to take place (see discussion below). Addition of an amino group of the analyte to the electrophilic $\alpha$-carbon in protonated DEE follows. The reaction is completed by a proton transfer cascade that ultimately produces a protonated ethoxy group that cleaves off as neutral ethanol. Since this reaction was not observed for monoamines (see discussion below), both functional groups in diamines must play a critical role. Therefore, we propose that the proton transfer to the ethoxy group occurs via the second amino group of the analyte, instead of a direct transfer from the first amino group to the oxygen via a four-membered transition-state. The fact that both protonated meta-phenylenediamine and $\mathrm{N}, \mathrm{N}$-dimethylaminoacetone (Table 2; discussed in detail below) were not found to form this product ion provides further support for the occurrence of a proton transfer between the two functionalities in the analytefor meta-phenylenediamine, the functional groups are oriented in such a manner that a proton transfer between them cannot take place; for $N, N$-dimethylaminoacetone, no proton is available to transfer after initial proton transfer and addition of the most nucleophilic group to the $\alpha$-carbon of protonated DEE has taken place.

Other bifunctional analytes. To test whether the reaction discussed above (addition - EtOH) also occurs for other basic bifunctional analytes besides aliphatic diamines, various other bifunctional compounds, including aromatic diamines, amino alcohols, amino acids, amino ketone, amino thiol, amino thioether, hydroxyether, hydroxyketone, diol, and diketone, were examined (Table 2). The PAs of these analytes range from 202 to $230 \mathrm{kcal} / \mathrm{mol}$, and hence are lower than those of aliphatic diamines $(228-245 \mathrm{kcal} / \mathrm{mol})$ and DEE ( $238 \mathrm{kcal} / \mathrm{mol})$. Since proton transfer to DEE is exothermic for these analytes, it is not surprising that this was observed for all of them (Table 2). The results are detailed below.

All amino alcohols studied (PAs from 222 to 230 $\mathrm{kcal} / \mathrm{mol}$ ) were found to react with DEE by forming the addition/elimination product (adduct - EtOH), in addition to an abundant proton transfer product (Table 2). This finding was somewhat surprising because it reveals that even after a highly exothermic (up to 16 $\mathrm{kcal} / \mathrm{mol}$ ) proton transfer from the protonated analyte to DEE (first step in Scheme 1), the collision complex does not always dissociate to separated proton transfer products, but addition of the analyte to protonated DEE is able to compete, leading to the formation of the addition/elimination product.

In sharp contrast to amino alcohols, the protonated amino acids, amino thiol, amino thioether, amino alkene, hydroxyether, hydroxyketone, diol, and diketone (PAs from 202 to $219 \mathrm{kcal} / \mathrm{mol}$ ) exclusively transfer a proton to DEE to form the proton transfer product $(\mathrm{m} / \mathrm{z}$ 117). This finding suggests that only analytes with PA greater or equal to $222 \mathrm{kcal} / \mathrm{mol}$ are able to undergo the diagnostic reaction. In addition to the proton transfer product, a fragment ion $(\mathrm{m} / \mathrm{z} 89)$ of the protonated DEE (ethylene loss) was observed for the reaction of protonated 1-hydroxy-2-propanone with DEE due to the big difference in the PAs $(\Delta \mathrm{PA}=36 \mathrm{kcal} / \mathrm{mol})$. Protonated $N, N$-dimethylaminoacetone has a high enough PA to undergo the diagnostic reaction $(\mathrm{PA}=227 \mathrm{kcal} / \mathrm{mol})$ but it exclusively transfers a proton to DEE due to the absence of a transferable proton after initial proton 
Table 2. Products $(\mathrm{m} / \mathrm{z}$ values and branching ratios) formed in reactions of various bifunctional analytes with DEE (estimated PA $=$ $238 \mathrm{kcal} / \mathrm{mol}$ )

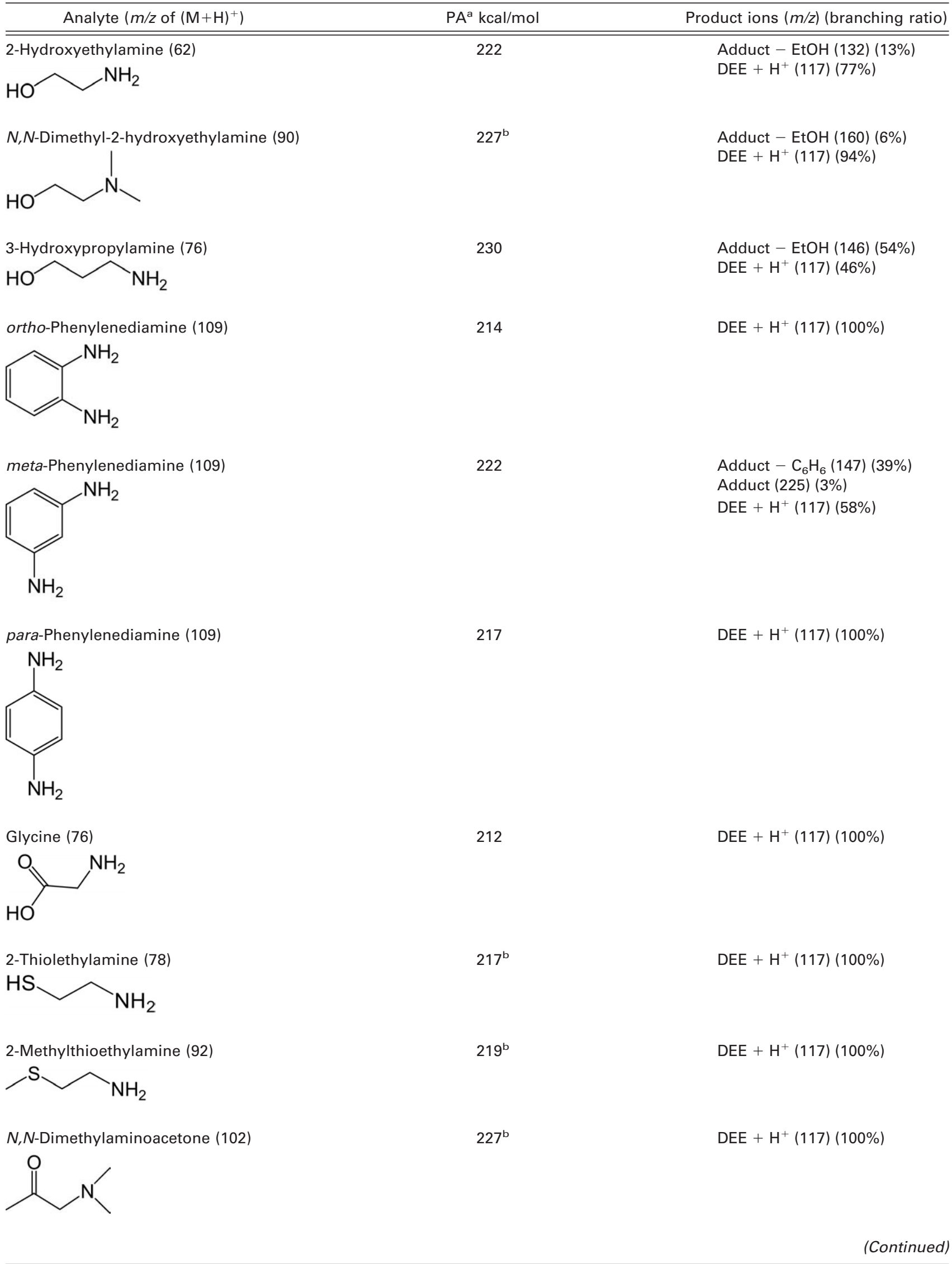


Table 2. Continued

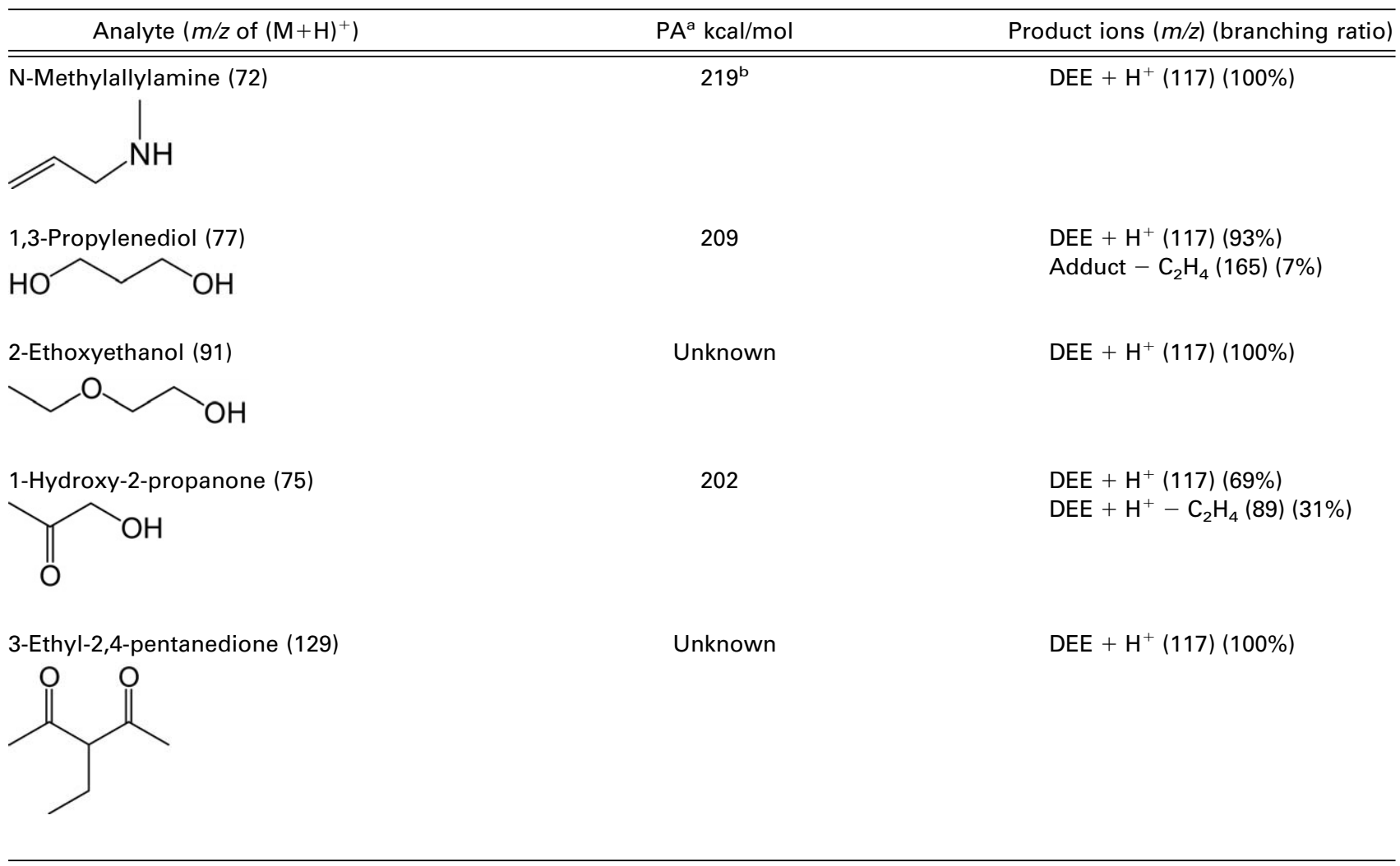

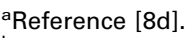

${ }^{b}$ Calculated at the B3LYP/6-31G(d) level of theory, using an isodesmic reaction scheme involving 2-hydroxyethylamine as a reference Brønsted acid.

transfer and addition of the most nucleophilic group to the $\alpha$-carbon of protonated DEE has taken place.

Three aromatic diamines (ortho-, meta- and paraphenylenediamine) were also studied (Table 2). In sharp contrast to aliphatic diamines (Table 1), no addition/EtOH elimination products were observed for the protonated aromatic diamines. Protonated ortho- and para-phenylenediamines react with DEE only via proton transfer due to the low PA of these diamines (214 and $217 \mathrm{kcal} / \mathrm{mol}$, respectively). In addition to the proton transfer reactivity, protonated meta-phenylenediamine reacts with DEE to form a new addition/elimination product (adduct $-\mathrm{C}_{6} \mathrm{H}_{6}$ ) and a stable adduct.

Nitrogen-, oxygen-, sulfur-, and phosphorus-containing monofunctional analytes. The selectivity of the neutral reagent (DEE) toward protonated basic bifunctional analytes $(\mathrm{PA} \geq 222 \mathrm{kcal} / \mathrm{mol}$ ) was further probed by examining the reactivity of various protonated nitrogen-, oxygen-, sulfur-, and phosphorus-containing monofunctional compounds whose PAs range from 192 to $235 \mathrm{kcal} / \mathrm{mol}$. All these ions transfer a proton to DEE to form the proton transfer product $(\mathrm{m} / \mathrm{z}$ 117; Table 3$)$, occasionally accompanied by a fragment ion of the proton transfer product $(\mathrm{m} / \mathrm{z}$ 89). The diagnostic product ion (adduct $\mathrm{EtOH})$ was not observed for any of these analytes, including those with PA $\geq 222 \mathrm{kcal} / \mathrm{mol}$, which further demonstrates that the formation of this product ion requires two functionalities in the analyte.

In addition to the proton transfer reactivity, some protonated amines (cyclohexylamine, hexylamine, and $\mathrm{N}$-ethylmethylamine), pyridine and $\mathrm{N}$-oxides react with DEE by forming a stable addition product (possibly a proton-bound dimer; Table 2). When the addition product $(\mathrm{m} / \mathrm{z} 216)$ formed in the reaction of protonated cyclohexylamine with DEE was isolated and subjected to SORI-CAD, only protonated DEE $(\mathrm{m} / \mathrm{z} 117)$ was formed. Hence, even energizing the reacting system does not result in formation of the diagnostic product ion for this monofunctional analyte.

Trifunctional analytes. To further probe the selectivity of the addition/elimination reaction of DEE for bifunctional analytes with $\mathrm{PA} \geq 222 \mathrm{kcal} / \mathrm{mol}$, various trifunctional compounds (PAs from 238 to $255 \mathrm{kcal} / \mathrm{mol}$ ) were examined (Table 4). The analytes with PAs greater than $249 \mathrm{kcal} / \mathrm{mol}$ were found to be unreactive toward DEE, likely due to the excessively high endothermicity $(>16$ $\mathrm{kcal} / \mathrm{mol}$ ) of the initial proton transfer step in Scheme 1 . One of the protonated triamines, 2,2'-diaminodiethylamine $(\mathrm{PA}=245 \mathrm{kcal} / \mathrm{mol})$, forms a product corresponding to addition and elimination of two ethanol molecules (adduct - $2 \mathrm{EtOH}$ ); Figure 2), possibly as shown in Scheme 2. This mechanism is analogous to that shown in Scheme 1, and it involves all three amino 
Table 3. Products $(\mathrm{m} / \mathrm{z}$ values and branching ratios) formed in reactions of protonated nitrogen-, oxygen-, sulfur- and phosphorus-containing monofunctional compounds with DEE (estimated PA $=238 \mathrm{kcal} / \mathrm{mol}$ )

\begin{tabular}{lcc}
\hline Analyte $\left(\mathrm{m} / \mathrm{z}\right.$ of $\left.(\mathrm{M}+\mathrm{H})^{+}\right)$ & $\mathrm{PA}^{a} \mathrm{kcal} / \mathrm{mol}$ & Product ions $(\mathrm{m} / \mathrm{z})(\mathrm{branching}$ ratio $)$ \\
\hline \hline Methylformamide $(60)$ & 204 & $\mathrm{DEE}+\mathrm{H}^{+}(117)(100 \%)$ \\
\end{tabular}

Dimethylformamide (74)

$\mathrm{DEE}+\mathrm{H}^{+}(117)(100 \%)$<smiles>CN(C)C=O</smiles>

Pyridine N-oxide (96)

$\mathrm{DEE}+\mathrm{H}^{+}(117)(79 \%)$<smiles>[O-][n+]1ccccc1</smiles>

Adduct (212) (21\%)

Isoquinoline $\mathrm{N}$-oxide (146)<smiles>[O-][n+]1ccc2ccccc2c1</smiles>

Butylamine (74)<smiles>CCCCN</smiles>

Hexylamine (102)<smiles>CCCCCCN</smiles>

Cyclohexylamine (100)<smiles>NC1CCCCC1</smiles><smiles>CCNC</smiles>

Diethylamine (74)<smiles>CCNCC</smiles>

Diisopropylamine (102)<smiles>CC(C)NC(C)C</smiles>

Unknown

220

221

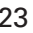

228

232
$\mathrm{DEE}+\mathrm{H}^{+}$(117) $(52 \%)$

Adduct (262) (27\%)

Adduct $-\mathrm{CH}_{3} \mathrm{COOC}_{2} \mathrm{H}_{5}$ (174) (21\%)

DEE $+\mathrm{H}^{+}(117)(100 \%)$

$\mathrm{DEE}+\mathrm{H}^{+}(117)(99 \%)$

Adduct (218) (1\%)

$\mathrm{DEE}+\mathrm{H}^{+}$(117) (91\%)

Adduct (216) (9\%)

$\mathrm{DEE}+\mathrm{H}^{+}(117)(94 \%)$

Adduct (176) (6\%)

DEE $+\mathrm{H}^{+}(117)(100 \%)$

$\mathrm{DEE}+\mathrm{H}^{+}(117)(100 \%)$ 
Table 3. Continued

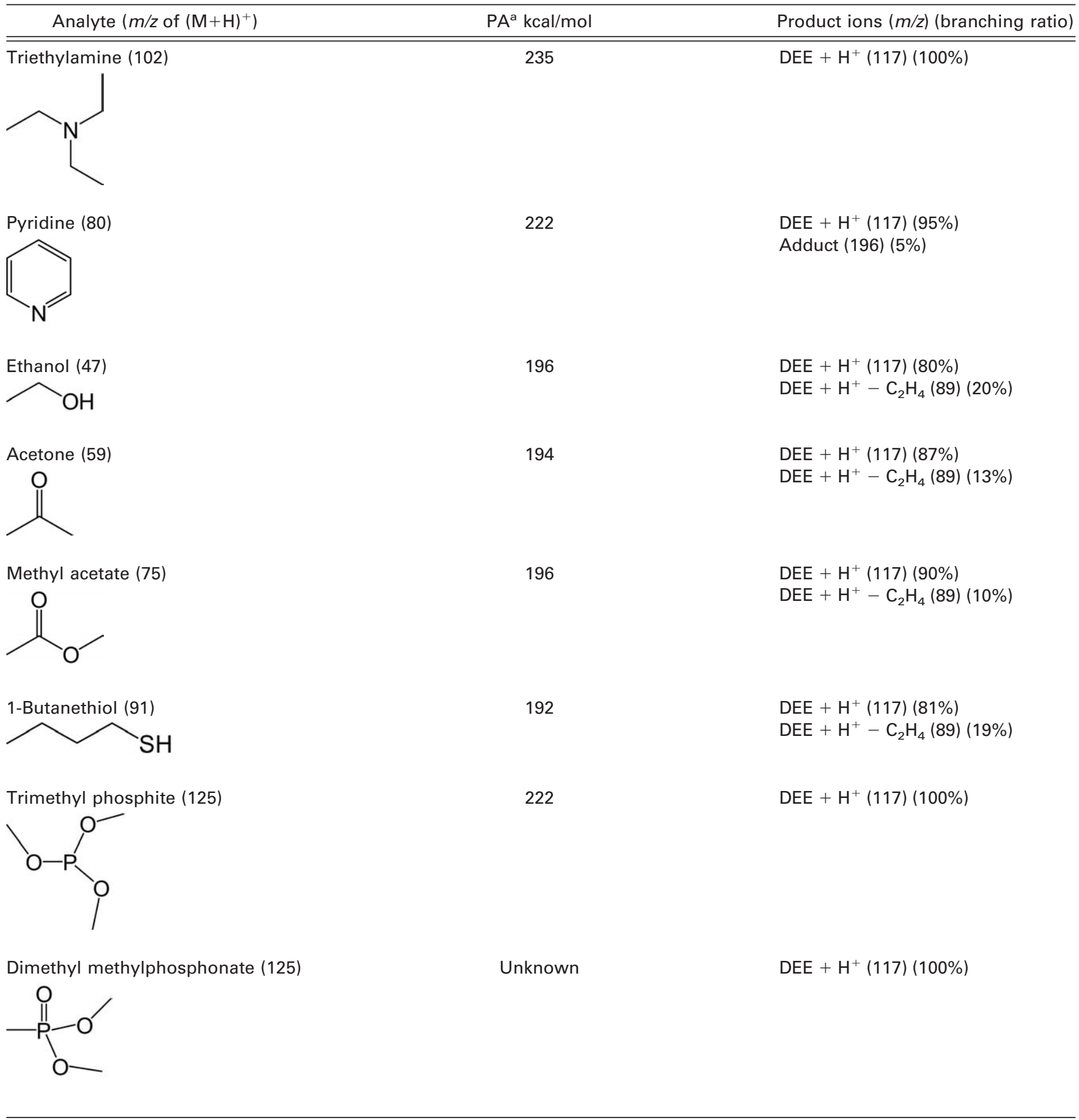

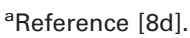

groups since no such products were observed for monoor diamines.

Only protonated lysine, with the lowest PA of the trifunctional analytes studied (238 $\mathrm{kcal} / \mathrm{mol})$, was found to undergo the diagnostic reaction with DEE (addition - EtOH). Although lysine contains three basic functionalities (two amino groups and one carboxylic acid group), it does not undergo elimination of two ethanol molecules like the triamine discussed above. However, SORI-CAD of the singly derivatized lysine (adduct - EtOH) results in elimination of $\mathrm{EtOH}$ (and also elimination of $\mathrm{NH}=\mathrm{C}\left(\mathrm{CH}_{3}\right) \mathrm{OEt}$, which demonstrates that the first derivatized site in lysine was one of the amino groups). Clearly, activation of the first derivatization product is needed to overcome the endothermicity of proton transfer from a basic amino group to the much less basic carboxylic acid group in the singly derivatized analyte (that has lost some of the initial solvation energy during ethanol loss), which is required for the elimination of the second ethanol molecule (Scheme 2). This finding suggests that in addition to basic bifunctional ana- 
Table 4. Products $(\mathrm{m} / \mathrm{z}$ values and branching ratios) formed in reactions of protonated triamines with DEE (estimated PA $=238$ $\mathrm{kcal} / \mathrm{mol}$ )

\begin{tabular}{lcc}
\hline Analyte $\left(\mathrm{m} / \mathrm{z}\right.$ of $\left.(\mathrm{M}+\mathrm{H})^{+}\right)$ & $\mathrm{PA}^{\mathrm{a}} \mathrm{kcal} / \mathrm{mol}$ & Product ions $(\mathrm{m} / \mathrm{z})$ (branching ratio $)$ \\
\hline \hline 2,2' -Diaminodiethylamine $(104)$ & $245^{\mathrm{b}}$ & Adduct $-2 \mathrm{EtOH}(128)(100 \%)$ \\
\hline $\mathrm{NH}_{2}$ & & \\
\hline
\end{tabular}

3,3'-Diaminodipropylamine (132)<smiles>NCCCNCCCN</smiles>

3,3'-Diamino-N-methyldipropylamine (146)<smiles>CN(CCCN)CCCN</smiles>

Lysine (147)<smiles>NCCCCC(N)C(=O)O</smiles>

$255^{c}$

$250^{c}$

238
No products

No products

aReference $[8 \mathrm{~d}]$.

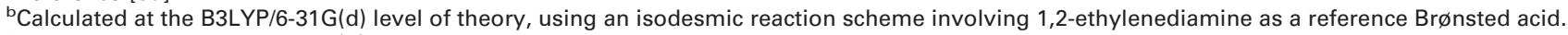
${ }^{c}$ Calculated at the B3LYP/6-31G(d) level of theory, using an isodesmic reaction scheme involving 1,3-propanediamine as a reference Brønsted acid.

lytes, also trifunctional analytes with two highly basic and one less basic functionality may undergo the diagnostic reaction.

\section{Conclusions}

Protonated aliphatic bifunctional analytes with PA between 222 and $245 \mathrm{kcal} / \mathrm{mol}$ (as well as lysine with three functionalities) have been shown to react with neutral DEE in a FT-ICR mass spectrometer in a selective manner by forming an addition/elimination

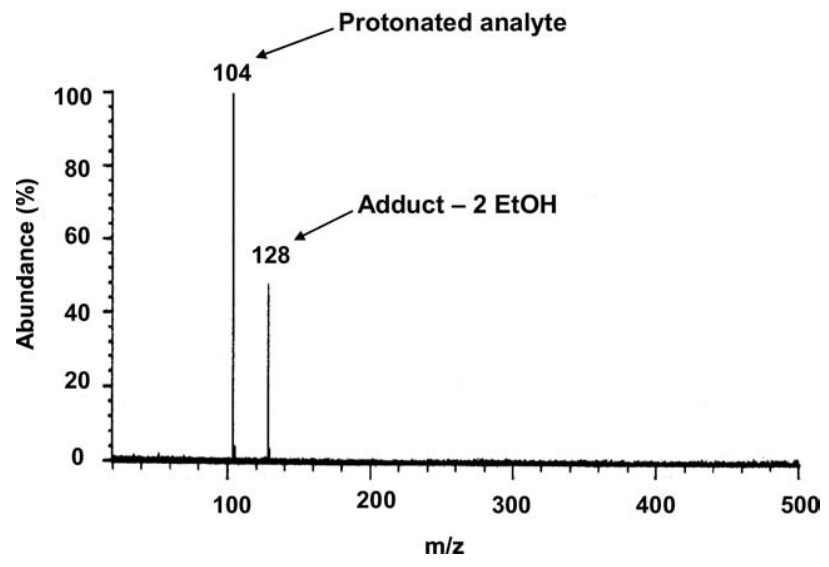

Figure 2. A mass spectrum measured after $5 \mathrm{~s}$ reaction of protonated 2,2'-diaminodiethylamine $(\mathrm{m} / \mathrm{z}$ 104) with DEE $(3.1 \times$ $10^{-8}$ Torr) in FT-ICR. This reaction results in a product that corresponds to addition with the loss of two ethanol molecules (adduct $-2 \mathrm{EtOH})(\mathrm{m} / \mathrm{z} 128)$. product ion (adduct - EtOH). The diagnostic reaction sequence involves proton transfer from the protonated analyte to the basic vinyl group in DEE, followed by the addition of the analyte to protonated DEE. The second step involves proton transfer from the addition site to the second functional group of the analyte, followed by transfer of a proton from this group to the ethoxy group of DEE (converting this into a good leaving group), which leads to elimination of an ethanol molecule (adduct - EtOH). Examination of the reactions of DEE with various mono-, $\mathrm{di}-$, and trifunctional protonated analytes containing amido, amino, N-oxide, hydroxy, carboxylic acid, keto, thio, thioether, alkene, phosphate, and phosphonate functionalities, demonstrates that this reaction is selective for analytes with two basic functional groups and PA between 222 and $245 \mathrm{kcal} / \mathrm{mol}$. However, the reaction does not occur for analytes wherein the functional groups cannot get into close proximity, such as some aromatic compounds, or for analytes wherein no transferable proton is available after initial proton transfer and addition of the most nucleophilic group to the $\alpha$-carbon of protonated DEE has taken place, such as dimethylaminoketone, since the mechanism involves proton transfer between the functional groups in the analyte. Bifunctional analytes with PA lower than $222 \mathrm{kcal} / \mathrm{mol}$, and monofunctional analytes with PA lower than $238 \mathrm{kcal} / \mathrm{mol}$, predominantly transfer a proton to DEE, while analytes with PA greater than $249 \mathrm{kcal} / \mathrm{mol}$ are unreactive. 

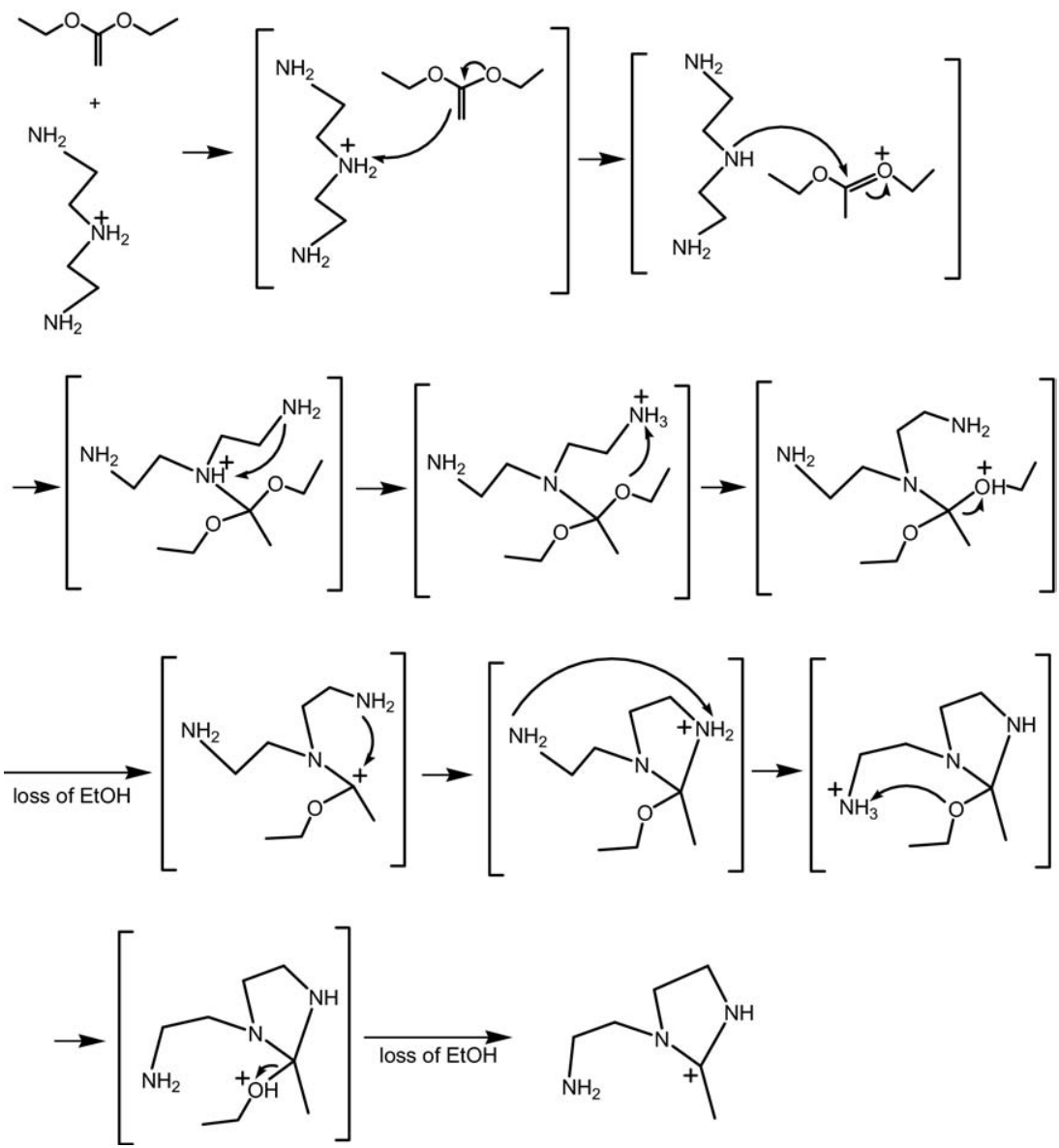

Scheme 2

\section{Acknowledgments}

The authors gratefully acknowledge the National Science Foundation for providing financial support for this work.

\section{Appendix A Supplementary Material}

Supplementary material associated with this article may be found in the online version at doi: 10.1016/ j.jasms.2009.02.020.

\section{References}

1. (a) Berger, S. J.; Lee, S. W.; Anderson, G. A.; Pasa-Tolic, L.; Tolic, N.; Shen, Y. F.; Zhao, R.; Smith, R. D. High-Throughput Global Peptide Proteomic Analysis by Combining Stable Isotope Amino Acid Labeling and Data-Dependent Multiplexed-MS/MS. Anal. Chem. 2002, 74, 49945000. (b) Wu, Y. The Use of Liquid Chromatography-Mass Spectrometry for the Identification of Drug Degradation Products in Pharmaceutical Formulations. Biomed. Chromatogr. 2000, 14, 384-396. (c) Smith, R. D.; Anderson, G. A.; Lipton, M. S.; Pasa-Tolic, L.; Shen, Y. F.; Conrads, T. P.; Veenstra, T. D.; Udseth, H. R. An Accurate Mass Tag Strategy for Quantitative and High-Throughput Proteome Measurements. Proteomics 2002, 2, 513-523. (d) Hopfgartner, G.; Husser, C.; Zell, M. Rapid Screening and Characterization of Drug Metabolites Using a New Quadrupole-linear Ion Trap Mass Spectrometer. J. Mass Spectrom. 2003, $38,138-150$

2. (a) Winger, B. E.; Kemp, C. A. J. Characterization of Pharmaceutical Compounds and Related Substances by Using HPLC FTICR-MS and Tandem Mass Spectrometry. Am. Pharm. Rev. 2001, 4, 55-63. (b) Peiris, D. M.; Lam, W.; Michael, S.; Ramanathan, R. Distinguishing $N$-oxide and Hydroxyl Compounds: Impact of Heated Capillary/heated Ion
Transfer Tube In Inducing Atmospheric Pressure Ionization Source Decompositions. J. Mass Spectrom. 2004, 39, 600-606.

3. (a) Bossio, R. E.; Marshall, A. G. Baseline Resolution of Isobaric Phosphorylated and Sulfated Peptides and Nucleotides by Electrospray Ionization FTICR MS: Another Step toward Mass Spectrometry-Based Proteomics. Anal. Chem. 2002, 74, 1674-1679. (b) Guan, S. H.; Marshall, A. G. Resolution and Chemical Formula Identification of Aromatic Hydrocarbons and Aromatic Compounds Containing Sulfur, Nitrogen, or Oxygen in Petroleum Distillates and Refinery Streams. Anal. Chem. 1996, 68, 46-71. (c) Yost, R. A.; Fetterolf, D. D. Tandem Mass Spectrometry (MS/MS) Instrumentation. Mass Spectrom. Rev. 1983, 2 1-45. (d) Schroeder, M. J.; Shabanowitz, J.; Schwartz, J. C.; Hunt, D. F.; Coon, J. J. A Neutral Loss Activation Method for Improved Phosphopeptide Sequence Analysis by Quadrupole Ion Trap Mass Spectrometry. Anal. Chem. 2004, 76(13), 3590-3598. (e) Levsen, K; Schwarz, H. Gas-Phase Chemistry of Collisionally Activated Ions. Mass Spectrom. Rev. 1983, 2, 77-148.

4. (a) Kenttämaa, H. I.; Cooks, R. G. Identification of Protonated $\beta$-Hydroxycarbonyl Compounds by Reactive Collisions in Tandem Mass Spectrometry. J. Am. Chem. Soc. 1989, 111, 4122-4123. (b) Kenttämaa, H. I.; Pachuta, R. R.; Rothwell, A. P.; Cooks, R. G. Experimental Study of the Potential Energy Surface of the Protonated Cyclohexene Oxide/cyclohexanone System. Isomerization, Dissociation, and IonMolecule Reactions of the Isolated Ions in the Gas Phase. J. Am. Chem. Soc. 1989, 111, 1654-1665. (c) Alvarez, E. J.; Brodbelt, J. S. Selective Ion-Molecule Reactions of Ether Reagent Ions with Nucleoside Antibiotics in a Quadrupole Ion Trap. J. Mass Spectrom. 1995, 30 625-631. (d) Moraes, L. A. B.; Gozzo, F. C.; Eberlin, M. N.; Vainiotalo, P. Transacetalization with Acylium Ions. A Structurally Diagnostic Ion/Molecule Reaction for Cyclic Acetals and Ketals in the Gas Phase. J. Org. Chem. 1997, 62, 5096-5103. (e) Gronert, S. Mass Spectrometric Studies of Organic Ion/Molecule Reactions. Chem. Rev. 2001, 101, 329-360. (f) Cooks, G. R.; Chen, H.; Eberlin, M. N.; Zhang, X.; Tao, A. W. Polar Acetylization and Transacetalization in the Gas Phase: The Eberlin Reaction. Chem. Rev. 2006, 106, 188-211. (g) Tian, Z.; Kass, R. S. Organic Gas-phase Ion Chemistry. Annu. Rep. Prog. Chem., Sect. B 2006, 102, 290-324. (h) O'Hair, A. J. R. Organic Gas Phase Ion Chemistry. Annu. Rep. Prog. Chem. B 2001, 97, 393-416. (i) Feng, Y. W.; Gronert, S. Gas Phase Organic Ion-Molecule Reaction Chemistry. Annu. Rep. Prog. 
Chem. B 1999, 95, 349-372. (j) Eberlin, M. N. Structurally Diagnostic Ion/Molecule Reactions: Class and Functional-group Identification by Mass Spectrometry. J. Mass Spectrom. 2006, 41, 141-156.

5. (a) Ranatunga, T. D.; Kennedy, J. M.; Kenttämaa, H. I. Disubstituted Boron Cations Cleave Carbonyl Bonds. J. Am. Chem. Soc. 1997, 119, 5200-5207. (b) Ranatunga, T. D.; Kenttämaa, H. I. Dicoordinated Boron Cations Dehydrate Organic Ethers in the Gas Phase. I. Am. Chem. Soc. 1992, 114, 8600-8604. (c) Kempen, E. C.; Brodbelt, J. Use of Trimethyl Borate as a Chemical Ionization Reagent for the Analysis of Biologically Active Molecules. J. Mass Spectrom. 1997, 32, 846-854.

6. (a) Brodbelt, J. S. Analytical Applications of Ion-Molecule Reactions. Mass Spectrom. Rev. 1997, 16, 91-110. (b) Watkins, M. A.; Price, J. M.; Winger, B. E.; Kenttämaa, H. I. Ion-Molecule Reactions for Mass Spectrometric Identification of Functional Groups in Protonated Oxygen-Containing Monofunctional Compounds. Anal. Chem. 2004, 76, 964-976. (c) Watkins, M. A.; Winger, B. E.; Shea, R. C.; Kenttämaa, H. I. Ion-Molecule Reactions for the Characterization of Polyols and Polyol Mixtures by ESI/FT-ICR Mass Spectrometry. Anal. Chem. 2005, 77 1385-1392. (d) Campbell, K. M.; Watkins, M. A.; Li, S.; Fiddler, M. N.; Winger, B.; Kenttämaa, H. I. Functional Group Selective Ion/Molecule Reactions: Mass Spectrometric Identification of the Amido Functionality in Protonated Monofunctional Compounds. J. Org. Chem. 2007, 72 3159-3165. (e) Watkins, M. A.; WeWora, D. V.; Li, S.; Winger, B. E.; Kenttämaa, H. I. Compound Screening for the Presence of the Primary $N$-Oxide Functionality via Ion-Molecule Reactions in a Mass Spectrometer. Anal. Chem. 2005, 77, 5311-5316. (f) Fu, M.; Duan, P.; Li, S.; Habicht, C. S.; Pinkston, S. D.; Vinueza, R. N.; Kenttämaa, H. I. Regioselective Ion-Molecule Reactions for the Mass Spectrometric Differentiation of Protonated Isomeric Aromatic Diamines. Analyst 2008, 132, 452-454. (g) Duan, P.; Gillespir, T. A.; Winger, B. E.; Kenttämaa, H. I. Identification of the Aromatic Tertiary N-Oxide Functionality in Protonated Analytes via Ion/Molecule Reactions in Mass Spectrometers. J. Org. Chem. 2008, 73, 4888-4894. (h) Gronert, S.; Huang, Renee, Li K. H. Gas Phase Derivatization in Peptide Analysis I: The Utility of Trimethyl Borate in Identifying Phosphorylation Sites. Int. J. Mass Spectrom. 2004, 231(2/3), 179-187. (i) Pyatkivskyy, Y.; Ryzhov, V. Coupling of Ion-Molecule Reactions with Liquid Chromatography on a Quadrupole Ion Trap Mass Spectrometer. Rapid Commun. Mass Spectrom. 2008, 22, 1288-1294. (j) Gronert. S.; O'Hair, R. A. J. Gas Phase Reactions of Trimethyl Borate with Phosphates and Their Noncovalent Complexes. J. Am. Soc. Mass Spectrom. 2002, 13, 1088-1098.

7. (a) Knochenmuss, R.; Zenobi, R. MALDI Ionization: The Role of In-Plume Processes. Chem. Rev. 2003, 103(2), 441-452. (b) Prakash, C.; Shaffer, C. L.; Nedderman, A. Analytical Strategies for Identifying Drug Metabolites. Mass Spectrom. Rev. 2007, 26, 340-369. (c) Lee, M. S. LC/MS Applications in Drug Development. John Wiley and Sons: New York, 2002.

8. (a) Stephenson, J. L. J.; McLuckey, S. A. Counting Basic Sites in Oligopeptides Via Gas-Phase Ion Chemistry. Anal. Chem. 1997, 69, 281-285. (b) Stephenson, J. L. J.; Schaaff, T. G.; McLuckey, S. A. Hydriodic Acid Attachment Kinetics as a Chemical Probe of Gaseous Protein Ion Structure: Bovine Pancreatic Trypsin Inhibitor. J. Am. Soc. Mass Spectrom. 1999, 10, 552-556. (c) Schaaff, T. G.; Stephenson, J. L.; Mcluckey, S. A. The Reactivity of Gaseous Ions of Bradykinin and Its Analogues with Hydro- and Deuteroiodic Acid. J. Am. Chem. Soc. 1999, 121 (38), 8907-8919. (d) Hunter, E. P.; Lias, S. G. Proton Affinity
Evaluation. In: NIST Chemistry Web Book, NIST Standard Reference Database Number 69 , Linstrom, P. J. Mallard, W. G., Eds. Nationa Institute of Standards and Technology: Gaithersburg MD, March 2003; http:/ / webbook.nist.gov.

9. (a) Campbell, J. L.; Fiddler, M. N.; Crawford, K. E.; Gqamana, P. P. Kenttämaa, H. I. Analysis of Polyethylene by Using Cyclopentadienyl Cobalt Chemical Ionization Combined with Laser-Induced Acoustic Desorption/Fourier Transform Ion Cyclotron Resonance Mass Spectrometry. Anal. Chem. 2005, 77, 4020-4026. (b) Campbell, J. L.; Crawford, K. E.; Kenttämaa, H. I. Analysis of Saturated Hydrocarbons by Using Chemical Ionization Combined with Laser-Induced Acoustic Desorption/Fourier Transform Ion Cyclotron Resonance Mass Spectrometry. Anal. Chem. 2004, 76, 959-963.

10. Dunbar, R. C. Infrared Radiative Cooling of Gas-Phase Ions. Mass Spectrom. Rev. 1992, 11, 309-339.

11. (a) Chen, L.; Wang, T. C. L.; Ricca, T. L.; Marshall, A. G. PhaseModulated Stored Waveform Inverse Fourier Transform Excitation for Trapped Ion Mass Spectrometry. Anal. Chem. 1987, 59, 449-454. (b) Marshall, A. G.; Wang, T. C. L.; Ricca, T. L. Tailored Excitation for Fourier Transform Ion Cyclotron Mass Spectrometry. J. Am. Chem. Soc. 1985, 107, 7893-7897.

12. Gauthier, J. W.; Trautman, T. R.; Jacbson, D. B. Sustained Off-resonance Irradiation for Collision-Activated Dissociation Involving Fourier Transform Mass Spectrometry. Collision-Activated Dissociation Technique that Emulates Infrared Multiphoton Dissociation. Anal. Chim. Acta 1991, 246, 211-225.

13. SuSu. T.; Chesnavich, W. Parameterization of the Ion-Polar Molecule Collision Rate Constant by Trajectory Calculations. J. Chem. Phys. 1982, 76, 5183-5185.

14. (a) Bartmess, J. E.; Georgiadis, R. M. Vacuum 1983, 33, 149-153. (b) Leeck, D. T.; Stirk, K. M.; Zeller, L. C.; Kiminkinen, L. K. M.; Castro, L. M.; Vainiotalo, P.; Kenttämaa, H. I. The Long-Lived Radical Cations of Simple Carbon Esters Isomerize to the LowestEnergy Structure. J. Am. Chem. Soc. 1994, 116, 3028-3038. (c) Thölmann, D.; Grützmacher, H. F. Reactions of Dihalobenzene Radical Cations with Ammonia in the Gas Phase. Reactivity Pattern for Nucleophilic Aromatic Substitution. J. Am. Chem. Soc. 1991, 113, 3281-3287.

15. Frisch, M. J.; Trucks, G. W. H.; Schlegel, B.; Scuseria, G. E.; Robb, M. A.; Cheeseman, J. R.; Montgomery, J. A. Jr.; Vreven, T.; Kudin, K. N.; Burant, J. C.; Millam, J. M.; Iyengar, S. S.; Tomasi, J.; Barone, V.; Mennucci, B.; Cossi, M.; Scalmani, G.; Rega, N.; Petersson, G. A.; Nakatsuji, H.; Hada, M.; Ehara M.; Toyota, K.; Fukuda, R.; Hasegawa, J.; Ishida, M.; Nakajima, T. Honda, Y.; Kitao, O.; Nakai, H.; Klene, M.; Li, X.; Knox, J. E.; Hratchian, H. P.; Cross, J. B.; Adamo, C.; Jaramillo, J.; Gomperts, R.; Stratmann R. E.; Yazyev, O.; Austin, A. J.; Cammi, R.; Pomelli, C.J.; Ochterski, W.; Ayala, P. Y.; Morokuma, K.; Voth, G. A.; Salvador, P.; Dannenberg, J. J.; Zakrzewski, V. G.; Dapprich, S.; Daniels, A. D.; Strain, M. C.; Farkas, O. Malick, D. K.; Rabuck, A. D.; Raghavachari, K.; Foresman, J. B.; Ortiz, J. V.; Cui, Q.; Baboul, A. G.; Clifford, S.; Cioslowski, J.; Stefanov, B. B.; Liu, G.; Liashenko, A.; Piskorz, P.; Komaromi, I.; Martin, R. L.; Fox, D. J.; Keith, T.; Al-Laham, M. A.; Peng, C. Y.; Nanayakkara, A.; Challacombe, M.; Gill, P. M. W.; Johnson, B.; Chen, W.; Wong, M. W.; Gonzalez, C.; and Pople, J. A. Gaussian 03, Revision B. 03; Gaussian, Inc., Pittsburgh PA, 2003. 